\title{
Cross-cultural adaptation of the Operationalized Psychodynamic Diagnosis (OPD-2) in Portugal
}

\author{
Adaptação transcultural do Diagnóstico Psicodinâmico Operacionalizado \\ (OPD-2) em Portugal
}

\author{
Carla S. Vicente, ${ }^{1}$ Rui Aragão Oliveira, ${ }^{2}$ Filipe Silva, ${ }^{3}$ Paulo Ferrajão, ${ }^{4}$ Sara Augusto, ${ }^{5}$ \\ Sandra Oliveira, ${ }^{6}$ Hugo Senra, ${ }^{7}$ Raquel Oliveira, ${ }^{8}$ Daniela Krieger ${ }^{9}$
}

\begin{abstract}
Background: The Operationalized Psychodynamic Diagnosis (OPD-2) is internationally established as one of the major instruments available for clinical diagnosis and scientific research, being frequently used as an auxiliary tool in the selection of therapeutic interventions.

Aims: 1) To describe the methodological aspects of the adaptation of the OPD-2 into Portuguese (Portugal and Brazil). 2) To assess inter-rater agreement for the different axes of the instrument when scoring clinical interviews.

Method: The cross-cultural adaptation involved translation of the instrument by different independent translators, whose versions were compared in discussion groups in order to develop a final Portuguese version. In the presence of discrepancies regarding the translation of original concepts, the authors of the original instrument were contacted for clarification. Five interviews were used to assess inter-rater agreement. Each subject participated in two interviews, conducted by an experienced clinical psychologist. The interviews were recorded, transcribed and then analyzed by the principal investigator and by three independent examiners.

Results: Axis IV (Structure) presented the highest inter-rater agreement (78\%). Axes I (Experience of illness and prerequisites for treatment) and III (Conflict) showed the lowest inter-rater agreement results (66 and $57.7 \%$, respectively).

Conclusions: Our results point in the same direction as previous studies conducted in other countries. In our sample, the OPD-2 presented an acceptable inter-rater agreement; however, further studies are needed to assess the instrument's reliability.

Keywords: Operationalized Psychodynamic Diagnosis, crosscultural adaptation, translation and adaptation methodology, psychological assessment instruments.
\end{abstract}

\section{Resumo}

Introdução: O Diagnóstico Psicodinâmico Operacionalizado (OPD-2) constitui-se internacionalmente como um dos principais instrumentos de diagnóstico clínico e de investigação científica, sendo frequentemente utilizado como uma ferramenta auxiliar na seleção de intervenções terapêuticas.

Objetivos: 1) Descrever os aspetos metodológicos do processo de adaptação transcultural do OPD-2 para a língua portuguesa (Portugal e Brasil). 2) Avaliar a concordância inter-avaliadores para os diferentes eixos do instrumento na cotação de entrevistas clínicas.

Método: A adaptação transcultural envolveu a tradução do instrumento por vários tradutores independentes. As versões resultantes foram confrontadas em grupos de discussão para a redação da versão final do instrumento em português. Na presença de divergências relacionadas à tradução de alguns conceitos originais, os autores do instrumento original foram contactados para esclarecimento. Para a avaliação da concordância inter-avaliadores, foram utilizadas entrevistas de cinco sujeitos. Cada um dos sujeitos participou de duas entrevistas, conduzidas por uma psicóloga com experiência clínica. As entrevistas foram gravadas, transcritas e posteriormente analisadas pela investigadora principal e por três examinadores independentes. Resultados: $O$ eixo IV (Estrutura) apresentou a maior concordância inter-avaliadores (78\%). Os eixos I (Vivência da doença e pré-requisitos para o tratamento) e III (Conflitos) obtiveram a menor concordância inter-avaliadores (66 e 57,7\%, respectivamente).

Conclusão: Nossos resultados apontam na mesma direção de estudos anteriores realizados em outros países. Na nossa amostra, o instrumento obteve razoável concordância inter-avaliadores, porém novos estudos são necessários para investigar a confiabilidade do instrumento.

Descritores: Diagnóstico Psicodinâmico Operacionalizado, adaptação transcultural, metodologia de tradução e adaptação, instrumentos psicológicos.

\footnotetext{
${ }^{1}$ Doutoranda, Departamento de Psicologia Clínica, Universidade de Évora, Évora, Portugal. ${ }^{2}$ Doutorado. Psicanalista. Unidade de Investigação em Psicologia e Saúde (UIPES), Instituto Superior de Psicologia Aplicada (ISPA), Lisboa, Portugal. ${ }^{3}$ Psicólogo clínico, Sociedade Portuguesa de Psicanálise, Sociedade Portuguesa de Psicossomática. ${ }^{4}$ Bolseiro de Doutoramento, UIPES, ISPA, Fundação de Ciência e Tecnologia (FCT). ${ }^{5}$ Doutoranda, Departamento de Psicologia Clínica, Universidade de Lisboa, Lisboa, Portugal. ${ }^{6}$ Doutorada. Psicanalista, CliniPinel, Lisboa, Portugal. ${ }^{7}$ Doutorado.Psicólogo clínico, clínica privada. ${ }^{8}$ Assistente técnica de investigação, UIPES, ISPA. ${ }^{9}$ Psicóloga clínica. Mestranda, Departamento de Psiquiatria, Universidade Federal do Rio Grande do Sul (UFRGS), Porto Alegre, RS, Brazil.

Submitted May 04 2012, accepted for publication Aug 01 2012. No conflicts of interest declared concerning the publication of this article.

Suggested citation: Vicente CS, Oliveira RA, Silva F, Ferrajão P, Augusto S, Oliveira S, et al. Cross-cultural adaptation of the Operationalized Psychodynamic Diagnosis (OPD-2) in Portugal. Trends Psychiatry Psychother. 2012;34(3):129-38.
} 


\section{Introduction}

\section{Brief introduction to the Operationalized Psychodynamic Diagnosis (OPD-2)}

In 1992, in Germany, Manfred Cierpka and a group of psychoanalysts, psychoanalytic psychotherapists, and psychiatrists founded a group called Operationalized Psychodynamic Diagnosis, or the OPD Task Force. ${ }^{1}$ Since its creation, the group has aimed at expanding the classification and description of mental disorder symptoms by adding some clinically attested psychodynamic dimensions to previous diagnostic systems. ${ }^{1,2}$

One of the reasons motivating the creation of the OPD group were the general limitations of existent diagnostic classification systems, such as the Diagnostic and Statistical Manual of Mental Disorders (DSMIII, DSM-IV), published by the American Psychiatric Association, ${ }^{3}$ and the International Classification of Mental and Behavioral Disorders (ICD-10), issued by the World Health Organization (WHO) ${ }^{4}$ in the context of psychodynamic psychotherapies. According to the OPD founders (Manfred Cierpka and Wolfgang Schneider), these diagnostic systems alienate the concept of neurosis and are primarily based on phenomenological and biological concepts, neglecting the validity and reliability of other categories of psychoanalytic diagnosis. ${ }^{1}$

A diagnosis centered on symptom descriptions provides few guidelines to psychodynamic therapists on how to guide their work, and does not provide information about the aspects underlying the individuals' mental functioning, such as interpersonal relations or intrapsychic conflicts. In addition, the level of structural integration of the patient's personality and the subjective experience of the disease are not taken into consideration in these classifications. ${ }^{1,2,5,6}$ As a result, the OPD Task Force developed a diagnostic inventory and a manual aimed specifically at experienced therapists. The authors' main objective was to promote specialized training and clinical application. ${ }^{1,2,5}$

The OPD-2 is a multiaxial tool for psychoanalytic diagnosis, based on five axes: Axis I, Experience of illness and prerequisites for treatment; Axis II, Interpersonal relations; Axis III, Conflicts; Axis IV, Structure; and Axis $\mathrm{V}$, Mental and psychosomatic disorders, in accordance with ICD-10's Chapter V(F). The first four axes are based on psychodynamic thought, derived from the psychoanalytic theory, and partially match psychoanalytic concepts (personality structure, intrapsychic conflicts, transference). The last axis is a point of connection with the diagnostic tool ICD-10.7 The instrument is intended for clinicians, who complete the forms covering each axis after performing one or more initial interviews lasting 1-2 hours each. The OPD-
2 therefore allows to identify dysfunctional relationship patterns, settings of internal conflicts, and the patient's structural conditions. It may be used in determining the focus of therapeutic interventions. ${ }^{1,2,5}$

\section{Main areas of application}

The creation of the OPD-2 has allowed the elaboration of reliable and differential diagnoses. In addition, when combined with other standardized instruments, the OPD2 has assisted in the development of psychotherapeutic treatment plans and in the evaluation of results.

In Germany, the OPD-2 is already considered an essential resource to certify the quality of interventions in patients undergoing psychodynamic psychotherapy in the context of hospital treatments, within the development the Quality in Psychodynamic Psychotherapy system (QPP). The OPD-2 allows the description of outpatient psychotherapy results and consequently the establishment of an operationalized psychodynamic diagnosis, including symptoms and systematic documentation of treatment progress.

This process is ensured by defining the changes that need to occur in the patient during the therapeutic plan. Such changes have as a starting point the categories identified as "problematic" in the OPD-2 initial evaluation. Treatment progress is assessed based on a common conceptual basis: the axes comprising the OPD- 2 are evaluated at different moments of the therapeutic process, guiding the therapeutic action through the definition of new treatment focuses. The OPD-2 also allows to evaluate the reduction of pre-existing symptoms, by defining the most appropriate therapeutic intervention for the patients and thus increasing their quality of life. ${ }^{1}$ The OPD-2 was not created with disciplinary or assessment purposes, but rather to improve our understand and judgment of which type of psychotherapy should be applied or will bring greatest benefit to the patient.

Even though the implementation of OPD-2 can be afforded by national public health institutions, the authors advocate the expansion of OPD-2 use also into private health care institutions, in order to develop internal systems of quality certification. ${ }^{1}$ The OPD- 2 can be applied with the following purposes:

1.to provide a better understanding of difficult treatment stages and help establish the focus of psychotherapy;

2. in evaluation and subsequent therapeutic indication. For example, patients with moderate to high levels of structural integration may join groups to work on the conflict pathology; patients with a low level of structural integration may be included in groups focusing on ego function deficits;

3.to access the patient's potential for change; 
4.as an evaluation system, complementary to ICD10-based diagnosis, applied at the beginning and the end of the therapeutic process, allowing the analyst to assess the changes taking place in the patient during the therapeutic process, as well as to collect indicators on factors that influence treatment adherence or non-adherence.

In addition to the clinical applications described above, the OPD-2 may also be useful in the evaluation and training of future psychotherapists, contributing to their professional certification in specialized areas of psychosomatic medicine and psychotherapy. ${ }^{2}$

At a different level, technical reports on psychosomatics and psychotherapy have been frequently requested from mental health experts in the legal framework (criminal, civil, social). According to the authors, ${ }^{1}$ OPD2 data may, for example, help support a forensic report generally based on a descriptive psychiatric diagnosis, as it enables the understanding of the individual's mental development. This could help understand the precise reasons and causes of a given act and predict a more reliable prognosis, namely by determining the probability of a given individual, with a given mental structure, incurring in the same act.

Thus, the original purpose leading to the creation of the OPD-2 was the development of an instrument that could enable an empirical investigation of the therapeutic process, largely supplanted by the possibilities of its practical application to other fields, which justifies its continuous dissemination and improvement.

\section{OPD-2 axes and specificities of the interview}

The OPD-2 manual provides a set of checklists and guidelines for clinical interviews that are specific and designed according to the specific nature of each psychodynamic dimension, in order to obtain a diagnosis for each axis. ${ }^{1}$ All axes, dimensions, and respective indicators are described in Table 1.

Table 1 - OPD-2 - Outline of each axis and respective directions

\begin{tabular}{|c|c|c|c|}
\hline & Axis & Dimensions & Indicators \\
\hline & $\begin{array}{l}\text { Experience of illness and } \\
\text { prerequisites for treatment }\end{array}$ & $\begin{array}{l}\text { Objective assessment of the patient's } \\
\text { illness/of the problem } \\
\text { Patient's experience, presentation, } \\
\text { and concepts of illness } \\
\text { Resources for and impediments to } \\
\text { change (Psychotherapy module) } \\
\text { Patient's experience, presentation, } \\
\text { and concept/s of illness } \\
\text { Resources for and impediments } \\
\text { to ch ange }\end{array}$ & $\begin{array}{l}\text { 1. Current severity of the illness/of the problem } \\
\text { 2. Duration of the disturbance/of the problem } \\
\text { 3. Experience and presentation of the illness } \\
\text { 4. Illness concepts of the patient } \\
\text { 5. Patient's concepts about change } \\
\text { 6. Resources for change } \\
\text { 7. Impediments to change } \\
\text { 5. Patient's concepts about change }\end{array}$ \\
\hline \multirow[t]{2}{*}{ II. } & Interpersonal relationships & Perspective A: The patient's experience & $\begin{array}{l}\text { Patient experiences herself as } \\
\text { Patient experiences others as }\end{array}$ \\
\hline & & $\begin{array}{l}\text { Perspective B: The experience of } \\
\text { others (also of the investigator) }\end{array}$ & $\begin{array}{l}\text { Others experience the patient as } \\
\text { Others experience themselves as }\end{array}$ \\
\hline \multirow{2}{*}{\multicolumn{2}{|c|}{ III. Conflict }} & Repetitive-dysfunctional conflicts & $\begin{array}{l}\text { 1. Individuation versus dependency } \\
\text { 2. Submission versus control } \\
\text { 3. Need for care versus autarky } \\
\text { 4. Self-worth conflict } \\
\text { 5. Guilt conflict } \\
\text { 6. Oedipal conflict } \\
\text { 7. Identity conflict }\end{array}$ \\
\hline & & Mode of processing of main conflict & $\begin{array}{l}\text { 1. Predominantly active } \\
\text { 2. Mixed but active } \\
\text { 3. Mixed but passive } \\
\text { 4. Predominantly passive } \\
\text { 9. Not ratable }\end{array}$ \\
\hline \multirow[t]{4}{*}{ IV. } & Structure & Cognitive abilities & $\begin{array}{l}\text { 1a. Self-perception } \\
\text { 1b. Object perception }\end{array}$ \\
\hline & & Regulation & $\begin{array}{l}\text { 2a. Self regulation } \\
2 \mathrm{~b} \text {. Regulation of object relationship }\end{array}$ \\
\hline & & Emotional communication & $\begin{array}{l}\text { 3a. Internal communication } \\
\text { 3b. Communication with the external world }\end{array}$ \\
\hline & & Attachment & $\begin{array}{l}\text { 4a. Attachment to internal objects } \\
\text { 4b. Attachment to external objects }\end{array}$ \\
\hline V. & $\begin{array}{l}\text { Mental and psychosomatic } \\
\text { disorders }\end{array}$ & $\begin{array}{l}\text { Mental disorders } \\
\text { Personality disorders } \\
\text { Somatic illnesses }\end{array}$ & $\begin{array}{l}\text { Main diagnosis/additional diagnosis } \\
\text { Main diagnosis/additional diagnosis } \\
\text { Main diagnosis/additional diagnosis }\end{array}$ \\
\hline
\end{tabular}


The first axis, Experience of illness and prerequisites for treatment, enables assumptions about the patient's ability and willingness to start a psychotherapeutic and psychosomatic treatment. Based on these assumptions, the need to carry out specific interventions, designed to increase motivation and promote the subject's ability to cope with their disease, can be deduced. The focus is not on maladaptive or pathological behaviors, but rather on the patient's experience, motivation, and personal resources. In a more specific way, this axis may even help prepare the patient for the psychotherapeutic process. ${ }^{1}$

Evaluation is performed using a usual psychodynamic interview and following some guidelines. Both the verbal and non-verbal contents of the interview should be considered when scoring each indicator. ${ }^{1,2,5}$

Axis II - Interpersonal relationships was designed to identify the individual's usual dysfunctional relationship patterns, and is operationalized through a clinical interview. The interview enables the understanding of recurrent dysfunctional patterns that the patient establishes with others in several areas of their life. These patterns are obtained by analyzing four categories of interpersonal behavior ${ }^{8}$ : how the patient perceives himself; how the patient perceives the others; how the others perceive the patient; and how the others perceive themselves in relation to the patient. Thus, it is possible to obtain a description of the patient's behavior and interaction patterns through two experiential perspectives: the patient's own perspective and the others' perspectives, including the interviewer/ psychotherapist's perspective. The final description is made using a standardized list of relational items, based on a circumplex model of interpersonal behavior. ${ }^{1,2}$

In this way, the subject's dysfunctional relational patterns and their persistence can be asserted. In other words, the relational dynamics obtained through the selection of items from the standardized list allows ascertaining the dysfunctional relationship patterns and their persistence. ${ }^{1}$

Axis III - Conflicts enables the understanding and identification of neurotic conflicts beyond the psychoanalytic notion of libido, with emphasis on a motivational development model. This allows the conceptualization and differentiation of the conflict's areas and structure, in a continuum model. ${ }^{1}$

Thus, the diagnosis of psychodynamic conflict involves its identification through deductive and inductive procedures regarding the patient's behavior. While the therapist/investigator becomes aware of a number of repetitive behaviors and experiences that allow the patient to reconstruct his pathway regarding his personal history and disease evolution, the therapist/ investigator also observes the effort made by the patient to solve his conflicts in an adaptive way (adaptation to life circumstances, existence of productive work, and personal relationships). Through the OPD-2, it is possible to recognize adjustments based on the presence of dysfunctions and on the fact that they lead to relational problems, which are, in turn, related to clinical symptoms and/or personality disorders. ${ }^{1,2,5}$ The following conflicts are assessed: individuation vs. dependence, submission vs. control, need for care versus autarky, self-worth conflict, guilt conflict, oedipal conflict, and identity conflict. ${ }^{1}$

To establish the diagnosis for this axis, the therapist/ interviewer should complete a specific checklist that provides general criteria to be considered in order to diagnose each conflict, as well as associated areas of life that may or may not evidence adaptation. The results of this checklist are based on the clinical interview designed for this axis, which is directed to the deepening of each conflict considering their psychodynamic specificities. ${ }^{1,7}$

As for Axis IV - Structure, diagnosis of the patient's structural patterns is performed based on their manifestations through the subject's behavior in the relationship. The interviewer experiences expressions of the patient's structure in the psychotherapeutic context. For example, when the patient shares their life experiences, it is possible to reach a general understanding of their psychic structure. Thus, the therapist has access to the patient's psychic structure through the information provided about their personal experiences and typical behavior, a concept closely related to the dynamics of the therapeutic relation. ${ }^{1}$

The interview based on this axis allows the observation of structural aspects that the interviewer should understand; knowledge should be particularly based on the personality theory and on the experience of diagnosis. Without this knowledge, the differentiation between counter-transference mechanisms, observation and introspection, would not be clear for the interviewer. ${ }^{7}$

The OPD-2 system does not address disorders corresponding to the traditional classification of "real diseases." Rather, it allows the understanding and identification of a predisposed or potential structure, which is inferred by the patient's interactions over the previous 2 years. The diagnostic checklist for this group encompasses four structural dimensions: awareness; regulation; communication; and attachment ability. Each dimension focuses directly on the self and on the object. Interview guidelines allow the interviewer/ therapist to obtain the necessary information in order to understand the patient's level of integration, i.e., it enables the interviewer/therapist to obtain information about the total structure. ${ }^{1,7}$ 
Axis V - Mental and psychosomatic disorders incorporates into the OPD-2 the same type of descriptive-phenomenological diagnostic classification as found in ICD-10 and DSM-IV, emphasizing the need for an accurate identification of the psychopathological phenomena that cannot be disregarded in psychodynamic psychotherapy. ${ }^{1,3,4}$

Unlike the procedure adopted in other axes, Axis $\mathrm{V}$ does not have a checklist, and therefore requires an indepth knowledge of diagnostic systems, including the ICD-10 and DSM- IV, and an extensive experience in diagnosis using these systems.

A descriptive clinical diagnosis of mental disorders according to the ICD-10 (Chapter V $[F]$ ), as stipulated for the first phase of the OPD- 2 interview, requires a complete identification or examination of the main symptoms of each chapter of ICD-10, including psychopathological criteria and their stability over time and during the course of the disease. ${ }^{3,4}$ In the context of clinical research questions, symptom checklists may also be used. These are external rating procedures that should be supplemented by other sources of information, such as information external to clinical history, behavior observation, etc. ${ }^{1}$

\section{Method}

\section{Methodological aspects of the cultural adaptation of the OPD-2 into Portuguese}

The translation and cultural adaptation of psychological assessment instruments presents significant challenges and difficulties related to ensuring an adequate adaptation of the original concepts into a second language. This process should ensure that the meaning of the constructs assessed is consistent for the people of a given culture or group; however, this consistency should also be preserved between different languages and cultures. ${ }^{9}$

In order to meet these requirements, in 2009 we started the process of translation and adaptation of the OPD2 into Portuguese. First, the instrument was translated into Portuguese by a group of independent translators comprising clinical psychologists, MSc and $\mathrm{PhD}$ candidates (with clinical experience), and two psychoanalysts with a $\mathrm{PhD}$. This methodology was based on literature findings that refer that the selected translators should be fluent in both languages and understand both cultures, but also have knowledge about the instrument's construction and the constructs assessed. ${ }^{10,11}$

Once the independent translations were completed, each individual version was compared with the others by the translators in discussion groups, in order to produce a final consensual version. This methodology assures preservation of the linguistic and connotative meaning of items, ensuring a better quality of the translation when compared with the traditional method of translation and back-translation. ${ }^{10}$

An example of the advantages of this methodology can be observed in Axis IV - Structure, item 2b Regulation of object-relationship, where the translators presented different formulations for the same item, with minor variations. One of the options ("Regulação da relação objectal," equivalent to "Regulation of the objectal relationship" in English) was considered to be the most adequate one taking into account the usual description found in the literature and the clinical application adapted to the Portuguese reality, enabling the maintenance of the construct present in the original version. ${ }^{12}$

However, in one of the last discussion sessions aimed at creating a synthetic version of the OPD2 in Portuguese, the translators were unable to reach a consensual solution for the formulation of some items, as for example Axis I, items 4.1.5.3 - Desired form of treatment: social environment, and 4.1.6.P1 - Psychological mindedness. These disagreements between translators probably resulted from the maintenance of a certain level of abstraction ${ }^{2}$ in the creation of the constructs, with qualities that ranged from a merely behavioral description to the metapsychological elaboration of concepts.

Aiming at a better understanding of the concepts and at insuring adequate content validity, the nonconsensual issues were referred to the OPD Task-Force (Manfred Cierpka/Matthias von der Tann) for further clarification. ${ }^{10}$ Finally, after consulting experts in the area and the creators of the test, the Portuguese version was formulated so as to encompass the sociocultural vicissitudes of each item, and simultaneously allow an inter-rater precision that is transversal to different theoretical models (through the operationalization of constructs applicable in clinical practice). ${ }^{13}$

Some authors advocate that the review process conducted by translators and authors of a given test should be performed according to a methodology that would enable its validity in a second language. Notwithstanding, most authors state that empirical evidence is necessary to support the validity of inferences concerning the translation's adequacy. According to Hambleton \& Patsula, this is achieved by means of a pilot study involving a small but representative sample. ${ }^{11}$

For the assessment of validity, the level of inter-rater agreement is determined after the independent judges score the interviews. High inter-rater agreement values indicated that categories are well operationalized and have a high content validity. ${ }^{2}$ 


\section{Sample}

This study was conducted at three private social solidarity institutions working with elderly people and patients with chronic diseases. Interviews were conducted in a small group of participants, comprised of five institution employees, mostly female. Participants' mean age was 40 years (range: 20-54). Most of them were social workers (2), followed by health care professionals (1), socio-cultural animators (1), and family helpers (1). In terms of qualifications, about $60 \%$ had a schooling level between the 9th and 12th grade, while $40 \%$ had a university degree.

\section{Procedures}

In order to assert the adequacy of translation, a pilot study was performed in which clinical interviews, based on the OPD-2, were conducted under a research project entitled "Understanding the burnout phenomena in caregivers of elderly and chronically ill people," with the aim of assessing how processes of a relational and conflictual nature can contribute to the onset of burnout syndrome (professional exhaustion) in professionals who deal with physically, mentally and socially vulnerable patients on a daily basis.

After authorization was granted by the institution's management, the five professionals were formally contacted and invited to participate in this study. The study aims and procedures were explained to participants, as well as the need to participate in two clinical interviews, each one lasting a minimum of 1 hour. Interviews took place at different weeks, were recorded, and lasted between and $1 \mathrm{~h} 30 \mathrm{~min}$ and $2 \mathrm{~h} 30 \mathrm{~min}$.

At first, a semi-structured interview with open-ended questions was conducted, with a particular focus on issues related to general information about work specificities and professional inter-subjectivity (when possible, a description of critical incidents was requested). Subsequently, the interview focused primarily on personal factors, with the objective of assessing interpersonal relationship patterns, intrapsychic conflicts, and mental structure; this interview was based on OPD-2 guidelines, as previously described. All procedures were conducted in accordance with guidelines from the Research Ethics Committees.

After the interviews, a coding system was used to score relevant dimensions arising from interviewee/investigator interaction, namely non-verbal communication events, emotional expression attunement, and also reactions and difficulties experienced by the investigator.

The procedure used to analyze interviews and rate the four OPD-2 axes was based on verbatim transcripts of each interview, with additional information on the issues mentioned in the previous paragraph, enabling a better understanding of transference and countertransference processes. Interviews were analyzed by three independent investigators (one psychoanalyst and two clinical psychologists) who belonged to the Portuguese OPD-2 research group and also completed the OPD-2 evaluation form. Finally, an inter-observer comparison of the scores was performed to evaluate the similarities and dissonances in the different axes.

In order to assess the level of agreement among different raters, percentage inter-rater agreement was calculated for each of the items comprising the OPD2 codification form. For each item, we calculated the percentage of agreement among different evaluators, based on the proportion of agreement in relation to the number of agreements and disagreements observed in the five interviews analyzed by the evaluators.

\section{Results}

Inter-rater analysis did not fulfill recommended statistical criteria given this is a preliminary study. In addition, the small sample size invalidates the use of statistical calculations such as intra-class correlation coefficient and weighted kappa. ${ }^{2}$ Therefore, before comparing inter-rater agreement, we conducted an exploratory data analysis, estimating scores for frequency per item and calculating percentages. Secondly, we defined a percentage $\geq 70 \%$ as a criterion to evaluate the agreement between raters. Unlike Pérez et al., who established $50 \%+1$ as their criterion, we chose to use a narrower and more conservative criterion, both because we are dealing with a non-clinical sample and because only four investigators analyzed the interviews.

Analysis of the five interviews allowed to identify the items and respective axes showing the highest levels of agreement and disagreement among raters. However, we chose to exclude Axis II - Interpersonal relations from this analysis, because further clarification and training by the investigators was considered necessary before a consistent and reliable evaluation could be made.

The axis with the highest level of agreement was Axis IV - Structure (78\%); however, in interviews 2 and 3, differences occurred in one out of nine items (Table 2). As for interview 2, in item 4a - Attachment to internal objects, the scores range from moderate levels of structural integration ${ }^{2}$ to not classifiable, ${ }^{9}$ corresponding to a $50 \%$ level of agreement (Table 3 ). Regarding interview 3, differences occurred in item $3 b-$ Communication with the external world, with integration scores ranging between high to moderate (1.5) and low (3), again with an agreement level of $50 \%$ (Table 3 ). 
However, the consistency of this axis can be explained by the fact that the understanding of clinical cases focuses on issues such as attachment, object relations, internal and external communication, and overall structure. Another hypothesis is that this is one of the most objective axes of the OPD-2, given it evaluates criteria that are directly observable in the interviewee's relationship with the patient.

Inter-rater differences were observed in Axis I Experience of illness and prerequisites for treatment and Axis III - Conflict. In Axis I, inter-rater differences were found in item 4 - Illness concepts of the patient (somatic and social factors), with a level of agreement ranging between 45 and $60 \%$. One of the investigators considered the somatic and social factors to be not classifiable, ${ }^{9}$ differing from the other two raters, who classified the three factors in a similar way: somatic, psychological and social (Table 4). Also, in item 5 - Patient's concepts about change, one of the raters believed that the types of treatment desired (physical, psychological, and social support - 60, 65 , and $70 \%$, respectively), were not classifiable ${ }^{9}$ (Table 4). Furthermore, in this axis, a low inter-rater agreement
(50\%) was observed for item 7 - Impediments to change, as one of the evaluators scored the item as not classifiable, disagreeing with the other raters (Table 4). These differences across raters can be justified by the difficulty faced by one of the raters in collecting sufficient evidence from the clinical material available in the interview so as to adequately score the items; as a result, that rater preferred to score items as not classifiable.

With regard to Axis III - Conflict, in the third interview, disagreement was observed in the assessment of individuation vs. dependency: the scores ranged from 1 (insignificant) to 3 (very significant), yielding an agreement level of $50 \%$ (Table 5 ). No further differences were observed, except for the main conflict and how conflict occurs.

In interview 4, the investigators had divergent opinions regarding the classification of the main conflict, alternating between 1 - Individuation versus dependency, 2 - Submission versus control, and 4 - Self-worth conflict. This disagreement also contributed to the divergence of opinions on how the conflict proceeds. Conversely, in interview 5, the disparities found in Axis III may be due to

Table 2 - Inter-rater analysis (\%)

\begin{tabular}{lccc}
\hline \multicolumn{1}{c}{ Axis } & Items & Items $\mathbf{Z}$ 70\% & \% \\
\hline I. Experience of illness and prerequisites for treatment & 21 & 14 & 66.6 \\
III. Conflict & 7 & 4 & 57.1 \\
IV. Structure & 9 & 7 & 77.7 \\
\hline
\end{tabular}

Table 3 - Axis IV - Structure

\begin{tabular}{|c|c|c|c|}
\hline Interview & Items & Range & $\%$ \\
\hline Interview 2 & $4 a-$ Attachment to internal objects & $\begin{array}{l}\text { Scores ranged from moderate levels of structural integration } \\
\text { to not classifiable }\end{array}$ & 50 \\
\hline Interview 3 & $\begin{array}{l}\text { 3b - Communication with the } \\
\text { external world }\end{array}$ & $\begin{array}{l}\text { Scores ranged between a high to moderate } \\
\text { and low level of integration }\end{array}$ & 50 \\
\hline
\end{tabular}

Table 4 - Axis IV - Structure

\begin{tabular}{llc}
\hline Axis & Items & \% \\
\hline $\begin{array}{l}\text { I. Experience of illness and } \\
\text { prerequisites for treatment }\end{array}$ & 4. Illness concepts of the patient (somatic and social factors) & 60 and 45 \\
& 7 Impediments to change & 50 \\
\hline
\end{tabular}

Table 5 - Axis III - Conflict

\begin{tabular}{|c|c|c|c|}
\hline Interview & Conflict & Range & $\%$ \\
\hline Interview 3 & 1. Individuation versus dependency & Scores ranged from 1 (insignificant) to 3 (very significant) & 50 \\
\hline \multirow[t]{4}{*}{ Interview 5} & 1. Individuation versus dependency & & \\
\hline & 2. Submission versus control & & \\
\hline & 3. Need for care versus autarky & Not secure of the diagnosis of underlying conflicts & 57 \\
\hline & & Significant and very significant & \\
\hline
\end{tabular}


the quality of the interview, which became an obstacle to completion of the conflict axis. As previously mentioned, one of the observers was not secure of the diagnosis of underlying conflicts, while the other three evaluators scored the first conflicts in a similar way, leading to a reduction in the percentage of inter-rater agreement (57\%). This discrepancy can also be explained by a certain rigidity of the less experienced raters, who objectively followed the scoring criteria presented in the OPD-2 manual.

However, the inter-rater differences expected for item 6.P1 - Psychological mindedness were not confirmed. This was one of the non-consensual items in the discussion sessions, with different meanings attributed by different translators, and therefore a low level of agreement was expected. Nevertheless, the level of agreement for this item was $75 \%$.

\section{Discussion}

The translation and cultural adaptation of a psychological assessment instrument is not limited to the mere translation of contents by independent translators, specialists in the subject and fluent in both languages, or to the revision of the translation by the OPD Task Force. As previously mentioned, ${ }^{11}$ in order to perform an empirical work that provides indicators regarding the consistency and validity of the translation, a pilot study has to be carried out. In order to comply with this last requirement, a pilot study was conducted with a small sample to obtain empirical evidence of the translation adequacy of OPD-2 into Portuguese.

The results found in this work are consensual with those found in the literature on the subject, ${ }^{1,2}$ indicating that high content validity results (determined by interrater agreement) are observed only in studies carried out for research purposes, through the use of interviews directed to the assessment of one or more OPD-2 axes, in comparison with results obtained when using the OPD2 in clinical practice or in a clinical setting. Hence, the need for further preparation and training in conducting OPD-2 interviews, covering all the axes, became evident. This need is reinforced by the fact that the OPD2 combines several interview methods according to the information that is sought, e.g., exploratory, structured, and unstructured.

Also, in accordance with their experience and with previous research, the authors observed that the OPD2 interview took longer than $1 \mathrm{~h} 30 \mathrm{~m}$, being unlikely completed in less time, and in some circumstances reaching 2-3 hours. ${ }^{3,11}$

Several papers designed to assess the reliability of OPD- $2^{1,2,5,14}$ have indicated an influence of two pre- conditions, namely, evaluator's clinical experience (approximately 2-3 years) and use of the OPD-2 in clinical practice. Therefore, the quality of the examined material, as well as the evaluator's clinical training and experience, play an important role in the quality of subsequent evaluations. ${ }^{1}$

As regards the evaluation of the degree of agreement between raters, we highlight that it was not possible to follow the statistical procedures recommended by the OPD-2 authors, namely intra-class coefficient correlations and weighted kappa, because of the preliminary nature and small sample of the present study. However, similarly to previous studies, we adopted other statistical procedures, in our case using a percentage $\geq 70 \%$ as a criterion to evaluate the degree of agreement. Although our methodology was similar to that employed by Pérez et al. ${ }^{14}$ we chose a narrower and more conservative criterion, because of our non-clinical sample and because we considered the evaluations of only four investigators.

These first clinical evaluations revealed problems in inter-rater agreement, especially in the diagnostic interpretation in Axis III - Conflict. The differences found in the scores appear to be related to difficulties in reaching a consensual assessment in the identification of the patient's central conflict, as well as in ordering the conflict's list. These results are similar to those of Pérez et al., ${ }^{14}$ who observed that this axis was the one with the greatest level of inter-rater disagreement between 15 evaluators. We hypothesize that these initial difficulties have to do with the clinician's tending to resist an attitude of evaluation oriented solely towards the identification of unconscious conflicts, as in clinical practice these professionals are usually focused on understanding the dynamics and main anxieties involved in object relationship. Conversely, these results may also be related to the fact that Axis III is one of the four more psychodynamic axes, where hypotheses are formulated based on the interpersonal relationship with the patient, which makes it a more subjective axis.

Another axis where discrepancies between evaluators were found was Axis I - Experience of illness and prerequisites for treatment. This is the most objective axis in terms of understanding the patient's problem, since it allows to assess the patient's experience, motivation, and personal resources regarding illness and change. The differences in the evaluations of this axis appear to be justified by the fact that the interviews were not conducted in a clinical setting (where specific complaints are present). As a result, in our sample, complaints were more diffuse and associated with the workplace.

With regard to Axis II - Interpersonal relations, some weaknesses were observed in terms of inter-rater 
scores, suggesting the need for improving knowledge and practice in order to ensure a greater homogeneity of scores. In this sense, we corroborate previous findings, ${ }^{14}$ confirming that this axis, like Axis III - Conflict, is more psychodynamic and implies a more subjective assessment by the investigators.

Regarding Axis IV -Structure, a slight divergence occurred in items $3 b$ - Communication with the external world and $4 \mathrm{a}$ - Attachment to internal objects, possibly related to a low level of structural integration in the first case and a lack of security in establishing diagnosis and proceeding to scoring in the second. However, this axis was the one with the highest levels of inter-rater agreement. The most relevant hypothesis to explain this homogeneity of scores is the fact that this axis is more objectively operationalized and easily measured through observable criteria, based on the interaction between clinician and patient. ${ }^{14}$

Considering the prerequisites for the implementation of OPD-2, it is vital that the therapists/interviewers have a basic understanding of psychodynamics, so as to understand the psychoanalytic constructs operationalized in the instrument. $1,2,14$

As revealed in previous studies, the qualifications required for a reliable use of the OPD-2 include, in addition to a thorough training in the use of the instrument, a minimum clinical experience of 2-3 years. These conditions are necessary as the OPD-2 interview should be non-structured and associated with a clinical exploratory approach, one that enables making some interpretations and clarifying certain aspects stated by the respondents, which cannot be deduced in an obvious way or based on common sense. ${ }^{2}$

During the interviews, some constraints were felt. Most importantly, the fact that the interviews were conducted in a non-clinical context, without an associated request for help, seems to have caused a greater level of defensiveness in the responses given by the participants, which focused primarily on labor aspects, seeming somewhat guarded in the discussion of personal issues. Another aspect that constituted a limitation is related with the use of a recorder, which was an inhibiting element to the respondent. Nevertheless, over the course of the interview, the participants gradually stopped focusing on accessories and started to interact more spontaneously. Another limitation possibly associated with audio recording refers to the fact that this method only captures the dialogue between two people, not reproducing aspects of the relational dynamics occurring between the dyad (investigator and respondent). However, we were concerned to take this into consideration when delineating the investigation, by providing the other investigators with personal notes collected by the interviewer where relevant dimensions of the dyad interaction were described, allowing a more comprehensive access to processes emerging during the interview, and not limiting it to the interview transcript.

Conversely, similarly to what is observed in the clinical context, our interviews were conducted under the practical constraints usually associated with the existence of a time limit, as they were performed during the participants' working hours. It had been originally agreed with the institution's management that each interview would not exceed 1 hour. ${ }^{5}$ However, since the first part of the interview focused on the working context, it was necessary to prolong this time so as to obtain more biographical data on the interviewee.

Additionally, the conduction of some interviews was tendentiously rigid; the concern of collecting as much information as possible to make an adequate evaluation of the OPD-2's axes led some interviewers to make closed questions and consequently interrupt the associative process during the interview. As argued by some authors, ${ }^{2,5}$ an approach using only one or two axes is easier and more consensual, given the demand for an extensive preparation and training for conducting an OPD-2 interview covering all the axes.

Thus, it seems to be of great importance to attend seminars given by OPD- 2 authors, in addition to the training provided by the OPD Task Force, which comprises different levels of expertise, as a means of achieving a deeper understanding of the evaluations of its various axes.

\section{Conclusion}

The OPD-2 is internationally established as a leading clinical diagnostic instrument for the identification of dysfunctional relationship patterns, configurations of internal conflicts, and the patient's structural conditions. Because it is related with the individual's current symptoms and pain, it may assist in determining the focus of therapeutic interventions.

The OPD-2 is already used in different countries and cultures (Germany, Britain, Italy, Chile, Australia), ${ }^{1,2,14}$ and is now in the process of being adapted into Portuguese, in a cross-cultural version for the populations of both Portugal and Brazil.

According to the first empirical evidence here described, the translation performed is adequate and presents good reliability, with results pointing in the same direction as previous studies conducted in other countries. Although our sample was not clinical, reasonable inter-rater agreement results were found. However, further studies are necessary to assess clinical samples and also larger samples, in order to assess the instrument's reliability. 


\section{References}

1. OPD Task-Force. Operationalized Psychodynamic Diagnosis OPD-2. Manual of diagnosis and treatment planning. Göttingen: Hogrefe \& Huber; 2008.

2. Cierpka M, Stasch M, Dahlbender R; El Grupo de Trabajo OPD. El sistema Diagnóstico Psicodinámico Operacionalizado (OPD): concepto, confiabilidad y validez. Rev Chil NeuroPsiquiatr. 2006;44:105-26.

3. American Psychiatric Association. Diagnostic and Statistical Manual of Mental Disorders - 4th edition (DSM-IV). Washington: APA; 1994.

4. World Health Organization. The ICD-10 Classification of Mental and Behavioral Disorders. Clinical descriptions and diagnostic guidelines. Geneva: WHO; 1993.

5. Cierpka M, Grande T, Rudolf G, Von der Tann M, Stasch M. The Operationalized Psychodynamic Diagnostics system: clinical relevance, reliability and validity. Psychopathology. 2007; 40:209-20.

6. Cierpka M, Stasch M, Grande T, Schauenburg H, De la Parra G, Rost R, et al. La evaluación primeras entrevistas psicoterapéuticas mediante el sistema diagnóstico psicodinámico operacionalizado (OPD2). Clin Invest Relac. 2010;4:221-35.

7. De la Parra G, Palacios JP, Stuardo VP, Alvarado L. Diagnóstico operacionalizado: indicación y planificación estratégica en psicoterapia psicodinâmica. Rev GPU. 2012;6:364-71.

8. Benjamin LS. Structural analysis of social behavior. Psychol Rev. 1974;8:392-425.
9. Van de Vijver F, Poortinga Y. Towards an integrated analysis of bias in cross-cultural assessment. Eur J Psychol Assess. 1997; 13:29-37.

10. Hambleton $H$. The next generation of the ITC test translation and adaptation guidelines. Eur J Psychol Assess. 2001; 17:164-72.

11. Hambleton $H$, Patsula L. Increasing the validity of adapted tests. J Appl Test Technol. 1999;1:1-30.

12. Aragão Oliveira R, Vicente $C$, Silva $F$, Ferrajão $P$, Oliveira $S$, Senra $\mathrm{H}$, et al. Cultural problems in adapting the OPD system in Portugal. 4th OPD International Conference; 2009 Oct; Heidelberg, Germany.

13. Geisinger KF. Cross-cultural normative assessment: translation and adaptation issues influencing the normative interpretation of assessment instruments. Psychol Assess. 1994;6:304-12.

14. Pérez F, Alvarado L, De la Parra G, Dagnino P. Diagnóstico psicodinámico (OPD-2): evaluación preliminar de la validez y confiabilidad inter-evaluador. Rev Chil Neuro-Psiquiatr. 2009;47:271-8.

\section{Correspondence}

Carla Susana Vicente

Clinical Psychology Department, Universidade de Évora

Av. Rovisco Pais, no 4, $1^{\circ}$ Dto

1049-001 - Lisbon - Portugal

Tel.: (+351) 91-7578563

E-mail: csvicent@gmail.com 